microcatheter. Eighteen aneurysms in 9 swine were surgically created using vein auto-grafts. Embolizations were performed in following device combinations: Novel Stent with coil (Group1: Novel stent, $\mathrm{n}=6$ ), commercially available stent (Group2: Neuroform stent, $\mathrm{n}=6$ ) with coil, and coil alone (Group3: coil, $\mathrm{n}=6$ ). Swine were sacrificed 14 days after stent deployment.

Results Mean aneurysm neck size was $6.24 \mathrm{~mm} \mathrm{(4.3-8.26}$ $\mathrm{mm})$, and average aneurysm fundus size was $9.0 \mathrm{~mm}$ (5.8$10.9 \mathrm{~mm}$ ). All cases in Group2 were treated by Neuroform stent. Average VER (volume embolization ratio) of Group1, Group2, and Group3 was 10.1\%, 10.9\%, and 10.5\%, respectively. There were no technical complications during novel stent deployment, such as migration, occlusion, etc. Favorable angiographic outcome, such as complete aneurysm thrombosis, was observed in 50\% of group3, and there was no favorable outcome in both group2 and 3. Recanalization rate of group1, 2 , and 3 is $50 \%(\mathrm{n}=3), 100 \%(\mathrm{n}=6)$, and 66\% $(\mathrm{n}=4)$, respectively. Aneurysmal rupture after procedure was observed in three cases from group 2, and two cases from group 3.

Conclusion The present study showed promising initial experience with the novel stent, particularly for its role as a low profile flow diverting stent and as an assisting stent for coil therapy.

Disclosures I. Kan: 1; C; Japan Agency for Medical Research and Development. Y. Murayama: 1; C; Japan Agency for Medical Research and Development. K. Karagiozov: None. A. Ikemura: None. I. Yuki: None. H. Takao: None. T. Kodama: None.

\section{E-072 50 SHADES OF GRADIENTS: DOES THE PRESSURE GRADIENT IN VENOUS SINUS STENTING FOR IDIOPATHIC INTRACRANIAL HYPERTENSION MATTER?}

${ }^{1} \mathrm{C}$ McDougall, ${ }^{2} \mathrm{~J}$ Beecher, ${ }^{2} \mathrm{~V}$ Shen Ban, ${ }^{1} \mathrm{M}$ Fiesta, ${ }^{1} \mathrm{~J}$ Barr, ${ }^{2} \mathrm{~J}$ White, ${ }^{1} \mathrm{R}$ Novakovic, ${ }^{1} G$ Pride, ${ }^{2} \mathrm{~B}$ Welch. ${ }^{1}$ Radiology, University of Texas Southwestern, Dallas, TX; ${ }^{2}$ Neurosurgery, University of Texas Southwestern, Dallas, TX

\subsection{6/neurintsurg-2016-012589.144}

Introduction Idiopathic intracranial hypertension (IIH) is a relatively uncommon, poorly understood disease that is often difficult to treat. First line medical and surgical therapies are often ineffective. Venous sinus stenosis is found in the vast majority of patients with IIH and venous sinus stenting (VSS) has been demonstrated to be effective in a select patient group. Identifying which patients will benefit from stenting remains unclear. One strategy is to measure the pressure gradient across the stenosis using retrograde transvenous manometry. Many authors have adopted a strategy whereby VSS is offered to patients with a pressure gradient above a certain threshold. This number is variable between different operators. In this study we reviewed the literature to try and establish what if any evidence exists to support a relationship between the pressure gradient across the stenosis and clinical outcomes. Materials and methods We systematically reviewed the English literature for studies reporting both the pressure gradients across the stenosis for each patient and the individual patient outcomes. Data was then analyzed for statistical correlations between the pressure gradient and the outcome.

Results We identified 85 patients from 13 studies in which both the pressure gradient and clinical outcomes were reported for each patient.

ANOVA comparing gradients with outcomes was not significant $(p=0.06)$. Student's $t$-test analysis of the groups with a dichotomization between the group with favorable outcomes and those with unfavorable outcomes was also not significant $(p=0.13)$. The pressure gradient was not found to be a statistically significant predictor of outcome on univariate logistic regression analysis $(p=0.15)$.

Conclusion Venous sinus stenting for IIH appears to have good clinical results in selected cases. However, from the available reported cases in the literature, there does not appear to be any correlation between an increasing pressure gradient across the region of stenosis and the chances of an improved outcome. These findings underscore the need for further study of IIH and reflect our incomplete understanding of its exact pathophysiology.

Disclosures C. McDougall: None. J. Beecher: None. V. Shen Ban: None. M. Fiesta: None. J. Barr: None. J. White: None. R. Novakovic: None. G. Pride: None. B. Welch: None.

\section{E-073 HIGH RESOLUTION MAGNETIC RESONANCE IMAGING OF INTRACRANIAL ANEURYSMS TREATED BY FLOW DIVERSION}

1J Guan, ${ }^{2} \mathrm{~S}$ McNally, ${ }^{3} \mathrm{~A}$ de Havenon, ${ }^{1} \mathrm{P}$ Tuassky, ${ }^{2} \mathrm{~S}$ Kim, ${ }^{1} \mathrm{M}$ Park. ${ }^{1}$ Neurosurgery, University of Utah, Salt Lake City, UT; ${ }^{2}$ Radiology and Imaging Sciences, University of Utah, Salt Lake City, UT; ${ }^{3}$ Neurology, University of Utah, Salt Lake City, UT

\subsection{6/neurintsurg-2016-012589.145}

The use of flow diverters to treat intracerebral aneurysms is highly successful with a low rate of morbidity of mortality.

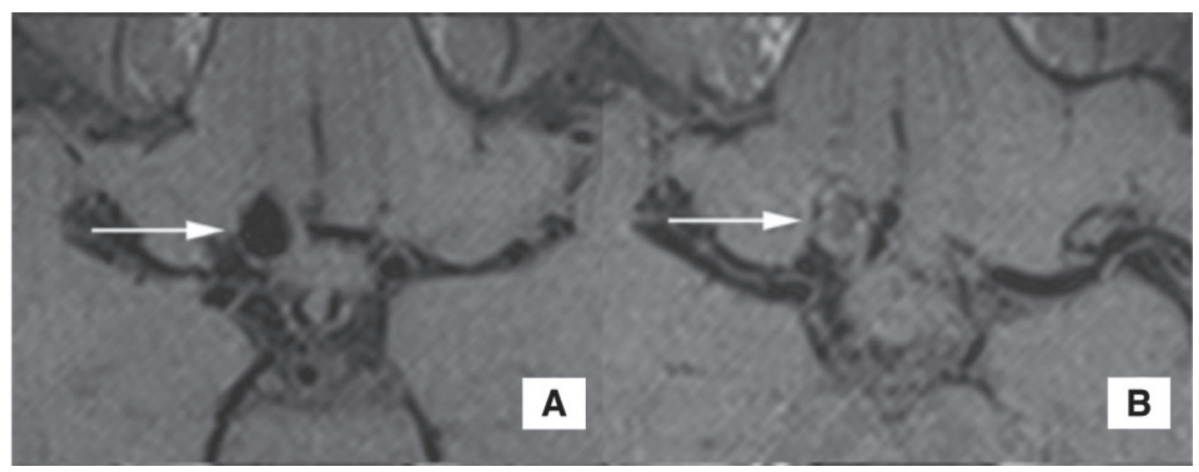

Abstract E-073 Figure 1 A) Pre-flow diversion 3D T1w Black Blood pre-contrast image; B) Post-flow diversion 3D T1w Black Blood pre-contrast image 